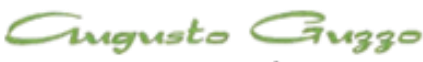

REVISTA ACADEMICA

\title{
As estratégias utilizadas no ensino da língua inglesa no pós- método para nativos e imigrantes digitais
}

\author{
Maria de Fátima Gomes Sanches ${ }^{1}$ \\ Recebido em: 01/03/2013. Aprovado em: 17/03/2013. Disponibilizado em: 26/06/2013
}

1. Maria de Fátima Gomes Sanches Professora de inglês da Faculdade e Colégio Eniac. Especialista em Língua Inglesa Universidade Ibero Americana. Líder de Intérpretes na Liber. E-mail: Sanches_fatimateacher@yahoo.com.br.

\section{Resumo}

A análise das estratégias utilizadas no ensino da língua inglesa no pós-método para nativos e imigrantes digitais foi uma investigação que exigiu um criterioso olhar sobre um período de atividades práticas. Neste tempo se observou a reação de aprendizagem dos alunos diante da técnica. Investigou-se se houve maior aquisição do idioma nos alunos submetidos a esse metodo comparado com os alunos de outros processos. Diante da hipótese de que há mudança mais significaticava nos alunos inseridos neste método buscou-se um comparativo para constatar ou negar a assertividade suposta. A proposta do método tem a pretensão de melhorar o ensino de uma segunda língua, neste caso a língua inglesa, para nativos e imigrantes digitais de uma forma mais eficaz em um tempo otimizado. A proposta afirma que o aluno desenvolverá as quatro habilidades: ouvir, falar, ler e escrever. Isso sem desconsiderar as diferentes habilidades e capacidades de cada aluno em sua diversidade. A aplicação das estratégia vem se repetindo atenta ao seu alcanse de aprendizagem. O ensino com essa prática para a aquisição da língua estrangeira tem afirmado atingir os melhores resultados no aprendizado de um contingente significativo de forma generalizada.

Palavras-chave: Estratégias, Ensino da língua inglesa, pós-método, Nativos e imigrantes digitais.

\begin{abstract}
The analysis of the strategies used for English teaching during post-method formatives and digital immigrants was an investigation that required a discerning view about a period of practical activities. The reaction learning of a student was observed forward the technique. It was investigated whether there was a greater language acquisition in students subjected to this method compared with students from other processes. Facing the assumption that there is more significative change in students inserted into the method it was searched a comparison to establish ordeny presumed assertiveness. This proposed method has the pretension of improving the teaching of a second language, in this case the English language for natives and digital immigrants in a more effective optimized at a time. The proposal asserts that a student will develop four skills: listening, speaking, reading and writing; with no disregard the different skills and abilities of each student in their diversity. The implementation of the strategy has been
\end{abstract}


repeating with close attention to their learning. Teaching with this practice for foreign language acquisition has affirmed achieve the best results in learning of a significant number of widespread form.

Keywords: Strategies, English teaching, post-method, formatives and digital immigrants. 


\section{Introdução}

Nos últimos tempos, o cenário mundial vem passando por mudanças econômicas, sociais e culturais em decorrência da globalização, da economia e das evoluções tecnológicas. Após a II Guerra Mundial, o ensino de Inglês ganhou importância de dimensões gigantescas no contexto mundial, a partir do momento em que se tornou cada vez mais necessário o domínio dessa língua, de modo que lhe permitisse comunicar-se naturalmente na língua estrangeira, através da fala e da escrita. Oliveira (199a, p.33) salienta que "a aprendizagem desperta processos internos de desenvolvimento que somente podem ocorrer quando o indivíduo interage com outras pessoas".

A obsessão por métodos de ensino de línguas estrangeiras atingiu seu nível mais elevado na metade do século XX (LEFFA, 1998， 2001; CELCE-MURCIA， 2001B; RICHARDS \& RODGERS, 1986 E 2001). Durante esse período de tempo vários métodos foram desenvolvidos ou, em alguns casos, modificados ou aperfeiçoados a partir de outros já existentes (Cf. BROWN, 2001; RICHARDS \& RODGERS, 2001; LARSEN-FREEMAN, 2003).

\section{Estilos e métodos de aprendizagem}

Entre os mais conhecidos é possível citar o Método Áudio-lingual, o Método Silencioso, a Sugestologia, o Resposta Física Total e o Método Comunicativo, também chamado, convenientemente, por alguns autores, de Abordagem Comunicativa (ALMEIDA FILHO, 1993, CELCEMURCIA, 2001b). Tais métodos foram motivados e influenciados, em grande parte, por teorias advindas da Linguística, da psicologia, principalmente da Psicologia da Educação e, em menor proporção, da Sociologia e da Sociolinguística, entre outras ciências e disciplinas. Dessa forma, conforme novas concepções e teorias surgiam nessas disciplinas, os métodos a serem analisados e criticados por novas perspectivas. Um exemplo claro a ser citado é o método Audiolingual. Fortemente fundamentado na psicologia behaviorista e na linguística estrutural, conforme essas correntes psicológicas e linguísticas eram questionadas, o método sofria consequentemente amplas e ferozes críticas. Em outras palavras, as influências da psicologia e da linguística sobre os métodos de ensino estimulavam críticas, adaptações, reformulações e o desenvolvimento de novas metodologias (MÁRCIO LUIZ, 2004). Mas, considerando o momento atual o qual chamamos de Pós-Método, podemos questionar: Por que nossos alunos são "viciados" em mensagens, jogos, músicas, tecnologia em geral e não conseguem se concentrar nas aulas? Talvez a resposta não seja tão simples quanto pareça. Será que suas atividades cognitivas também mudaram? Eles realmente aprendem de maneira diferente se comparados a outras gerações de alunos?

Qualquer novidade tecnológica na mão deles é rapidamente dominada e usada. Mark Prensky tem uma explicação para essas perguntas: segundo ele, os alunos que já cresceram na era tecnológica são chamados de nativos digitais. Eles passaram suas vidas inteiras em contato com computadores, videogames, músicas digitais, brinquedos, Internet, Twiter, Facebook, etc. Dr. Bruce D. Berry da Baylor College of medicine disse que diferentes tipos de experiências levam a diferentes estruturas do cérebro. Segundo ele os cérebros de nossos alunos têm mudado fisicamente e são diferentes dos nossos, como resultado de como cresceram e se 
desenvolveram. Verdade ou não, o que podemos dizer com certeza é que eles mudaram na maneira de pensar e aprender.

São chamados nativos digitais todos os que nasceram na era digital e que dominam a linguagem digital. São chamados de imigrantes digitais todos os que precisaram aprender a usar as ferramentas digitais. Necessário se faz salientar que dependendo da sala de aula podemos ter tanto alunos nativos digitais quanto alunos imigrantes digitais e que o professor também pode ser nativo ou imigrante. Sendo assim, como ensinar outro idioma para um público tão diferente?

Segundo Howard Hendricks:

A ideia nessa lei é a de que, antes de ser professor, sou um aprendiz, um "estudante" ensinando estudantes. Estou dando continuidade ao processo de aprendizagem. "Precisamos adotar a atitude de que ainda não chegamos lá. Quem aplica esse principio didático na prática está sempre se perguntando: Como posso melhorar meu ensino?"Encaremos esse fato da seguinte maneira: enquanto estivermos vivos estaremos aprendendo; e enquanto estivermos aprendendo estaremos vivos.

\section{Desenvolvimento: métodos e modos}

A palavra método vem do grego méthodos, uma palavra composta por meta, que denota sucessão, ordenação e hodós, que significa via, caminho. Partindo dessa etimologia, é possível afirmar que o conceito de método está relacionado a um caminho que, seguido de forma ordenada, visa chegar a certos objetivos, fins, resultados, conceitos, etc.

Para os professores se faz necessário estar bem informados sobre pontos fracos e fortes de cada método e decidirem quando usá-los ou não, dependendo da classe e dos alunos de cada sala conforme Brown (2001).

\subsection{Método Audiolingual}

$\mathrm{Na}$ opinião de Richards and Rodgers (2001) o método audiolingual apresenta oportunidades para que os alunos pratiquem estruturas pré-selecionadas com exercícios em sala. Há preocupação com a pronúncia e estruturas gramaticais. Os "drills", treinamento auditivo com repetição simultânea, são largamente utilizados. Não é permitida a tradução e os alunos precisam memorizar estruturas. O professor controla os alunos prevenindo qualquer tipo de conflitos com a teoria.

\subsection{Método Comunicativo}

O método comunicativo é dialogado. Como aponta Richards and Rodgers (2001), os diálogos são usados para guiar os alunos ao aprendizado da comunicação. Pode-se usar os "drills", mas não tão frequentes como no audiolingual. Todos os diálogos são contextualizados para que os alunos tenham uma compreensão maior do que está aprendendo. A linguagem é criada individualmente pelo aluno sem levar em consideração a pronúncia. O professor não tem o controle exatamente da linguagem que o aluno está usando.

[...] O ensino comunicativo trouxe conceitos de ensinar e aprender línguas calcados na interação e negociação de sentidos em torno de assuntos ou temas de relevância e interesse dos aprendizes assim como a subscrição de um certo conceito de linguagem como ação social e não mais como um conjunto de blocos linguisticos bem descritos por métodos científicos rigorosos. O professor de língua estrangeira deve, portanto, ter a 
preocupação constante de oferecer um ambiente favorável para o desenvolvimento das habilidades de compreensão/produção oral e compreensão/produção escrita por meio de diferentes atividades. Seu papel é facilitar os caminhos que conduzem à aprendizagem da língua em estudo, fornecendo instrumentos necessários para que discentes atinjam com sucesso os resultados desejados. (FILHO, Almeida, 2001).

\subsection{Método direto}

Não há teoria para esse processo de aprendizagem segundo Richards and Rodgers (2001). Aqui os alunos são pressionados a usar a linguagem corretamente. A gramática é aprendida por suposição, não há escrita e nem palavras soltas. A correção da pronúncia e da gramática é enfatizada. Não há livro e sim planos de aulas. $O$ professor organiza materiais para promover a comunicação. $\mathrm{O}$ modelo é dos alunos, eles precisam interagir fazendo perguntas e criando respostas.

\subsection{Método Gramática/Tradução}

O foco principal é a leitura e escrita e não a fala na opinião de Richards and Rodgers (2001). É importante a tradução e memorização de regras gramaticais. As palavras do vocabulário são traduzidas e memorizadas. E o aluno é passivo. O professor enfatiza a aplicação das regras gramaticais para que se faça a tradução das sentenças.

\subsection{Abordagem Natural}

Nesta abordagem Richards and Rodgers (2001) diz que há uma teoria gramatical, aprendida de forma natural. O aluno precisa estar consciente monitorando e corrigindo a sua fala. A estrutura e o vocabulário são enfatizados e o professor usa mímicas, gestos, gravuras e atividades comunicativas. O professor decide quando o aluno está pronto para falar.

[...] a ordem natural, previsível, em que adquirimos as regrasda língua materna também é seguida na aquisição da Segunda Língua. Essa ordem natural parece não ser determinada pela simplicidade da regra que está sendo adquirida e parece não corresponder a ordem em que as regras gramaticia $s$ são ensinadas em aulas de línguas. Dos estudos feitos em inglês 9como a língua materna) e em russo e espanhol (como língua estrangeira) deduz-se que a hipótese baseada na ordem natural de aquisição de uma língua é válida, e razoavelmente um fenômeno universal. (KRASNEN, 1982).

\subsection{Modo silencioso}

O autor Richards and Rodgers (2001) diz que o modo silencioso é baseado mais na aprendizagem cognitiva do que em argumentos afetivos. O professor é a autoridade na aula e o aluno é passivo. Geralmente o professor controla a situação e o aluno é submisso. Há uma apresentação rápida, o professor pode corrigir o aluno e ajudá-lo, mas a característica do modo silencioso é deixar que os alunos descubram por si mesmos os fatos e princípios. $O$ material é usado para introduzir vocabulário, verbos e sintaxe. $O$ aluno percebe por si mesmo enquanto o professor faz mímicas e gestos, porém não tem proximidade com o aluno. 


\subsection{Sugestologia}

Neste processo de aprendizagem de acordoo com Brown (2001) os alunos precisam deixar suas mentes relaxadas além de analisarem a gramática e usarem seus cadernos para anotarem algo importante. Nele não há material e o professor tenta ser uma espécie de conselheiro. Os grupos são pequenos e os alunos são vistos como clientes.

A tradução, memorização e regras gramaticais são aceitas. Acredita-se que o cérebro humano pode processar grandes quantidades de materiais desde que em condições corretas de aprendizado. A música é muito usada para que os alunos relaxem. Ensino tradicional no que se refere a vocabulário e gramática. A ansiedade é negativa, o professor é autoridade e o aluno passivo submisso totalmente ao método.

\section{Resposta total física}

A teoria é estrutural, o aluno precisa ouvir antes de falar e não há ansiedade. $\mathrm{O}$ diálogo entre os aprendizes é transcrito para fixar a linguagem formal. Os alunos se tornam independentes e buscam a proficiência oral. Segundo Brown (2001), qualquer pessoa que faça um breve estudo histórico sobre o ensino de línguas estrangeiras perceberá facilmente que a busca por um método perfeito foi durante muito tempo uma obsessão.

[...] o conhecimento de vários métodos (não a ausência deles) deve conduzir a uma prática coerente e plural no ensino de uma língua, onde grande variedade de atividades possa ser empregada de forma a facilitar, acelerar ou otimizar o processo de ensino. (BROWN, 2001)

Para Prabhu (1992) o uso de qualquer método depende de um contexto, ou seja, antes de decidir qual método usar, o professor precisa fazer as seguintes perguntas: Para quem vou ensinar? - quais as circunstâncias? Quais são os objetivos dos alunos? - Muitas vezes um método é bom para alguns alunos e não é tão eficiente para outros. Em outras salas se faz necessária mais motivação para que o grupo mostre interesse em suas atividades. Não é o método que é mais importante, mas como desenvolver cada atividade indo ao encontro das necessidades de cada aluno.

Prabhu (1992) também não diz para que se descarte algum método, mas sim para que se adotem diferentes métodos para diferentes contextos. Quando algum método considerado bom é implantado, pode-se perceber que com o tempo alguns professores usam tal método mecanicamente, o que não é aconselhável. Faz-se necessário o uso do senso de identificação de cada grupo e entendimento do que é necessário para cada um.

Considerando o momento atual chamado de Pós-método, não podemos esquecer-nos dos nativos digitais os quais, segundo Prensky (2001), estão tão habituados a receber informações com uma velocidade espantosa que não demonstram interesse nas aulas de inglês. Os nativos digitais preferem jogos a trabalho sério, preferem baixar músicas ou enviar mensagens a prestar atenção quando o professor está explicando algo novo. Então, observamos que é muito mais interessante usar tecnologia do que assistir a uma aula onde o aluno só ouve ou observa o professor. Eles preferem atividades múltiplas e gostam de processos paralelos. Os nativos digitais acham que o aprendizado deveria ser mais divertido e interessante, mas não conseguem se concentrar durante muito tempo em somente um assunto. Por outro lado, Prensky (2001), descreve os imigrantes digitais como pessoas que tem "sotaque" no novo idioma, o idioma tecnológico. Os imigrantes são pessoas que cresceram sem 
tecnologia e que precisaram aprender a usálas, mas que preferem imprimir algo para ler a ler um texto no monitor de seu computador; preferem ler um manual de instrução a assumirem que o programa por si só nos ensina como usá-lo. São pessoas com um pé no passado e um no presente. Os quais aprenderam passo a passo e devagar, uma informação de cada vez. Os imigrantes digitais acham que o aprendizado não deveria ser divertido, mas conseguem concentrar-se por mais tempo em somente um assunto.

As abordagens de John Milton Gregory (1886) que viveu no século século XVII (1822/1898) foi um líder educativo e deixou ideias revolucionárias acerca da aprendizagem que concluem esta investigação.

\section{Considerações Finais}

A tarefa do professor é despertar a mente do aluno, é estimular ideias, através do exemplo, da simpatia pessoa, e de todos os meios que puder utilizar para acordar a inteligencia. O maior dos mestres disse há dois mil anos que "a semente é a palavra". O verdadeiro professor é aquele que revolve a terra e planta a semente.

É preciso conversar com os alunos e conhcer as suas necessidades para saber qual o objetivo do seu curso de inglês. Cada aluno que vai aprender um novo idioma apresenta características específicas que devem ser consideradas e respeitadas, tanto para nativos quanto para imigrantes digitais.

A habilidade para modificar e construir a aula é do professor, mas ele precisa conhecer a realidade de cada aluno para atingí-lo usando diferentes estratégias e médodos. Conhecendo os métodos, as tecnologias, e utilizando ferramentas que ajudem o aluno no seu aprendizado, o professor despertará a inteligencia para os idiomas adormecida em cada um.

No pós-método, o professor tomado de conhecimento e conhecedor da realidade de cada aluno, deve criar possibilidades de aprendizagem e não alunos passivos que recebem muitas informações, mas não sabem o que fazer com elas. Há diversas abordagens, os alunos encontram sentido para suas aulas de inglês e tornam-se participantes ativos no processo, o professor cria oportunidades e usa tecnologias disponíveis para que os alunos aumentem suas possibilidades potencializando $\mathrm{O}$ aprendizado de acordo com suas necessidades e melhorando sua comunicação.

\section{Referencias Bibliograficas}

1. ALMEIDA Filho, J. C. P. Dimensões comunicativas no Ensino de Línguas. Campinas, Pontes, 1993.

2. ALMEIDA Filho, José Carlos Paes de. Linguística aplicada - Ensino de línguas e comunicação. 2ed. Campinas: Pontes e ArteLíngua, 2007.

3. BROWN H. D. and Wesley, Addison. Teaching by Principles. White Plains, NY: LONGMAN, 2001.

4. CELCE-MURCIA, M. Teaching English as a Second or Foreign Language. Third Edition. London, Heinle Heinle - Thomson Leraning, 2001.

5. DAVIES, P and Pearse, E. Success in English Teaching. New Yorl, USA: OXFORD, 2000.

6. GREGORY, John Milton. As sete leis do ensino. Boston MA: Congregação da Escola Dominical e Sociedade Publisshing; 1886. 
7. GREGORY, John Milton. Ensinando para transforrmar vidas. Ed Betania $1^{\mathrm{a}}$. Ed. Belo Horizonte MG. 1991

8. GUIMARÃES, R. Teaching Light Teaching Better. São Paulo: SENAC, 1997.

9. KUMARAVADIVELU, B. Toward a Postmethod Pedagogy. TESOL Quarterly. Vol. 35, No. 4. 2001.

10. PRABHU, N. S. There is no best method Why? TESOL Quarterly, V. 24, 1994.

11. PRENSKY, Marc. Digital Natives, Digital Immigrants. On the Orizon, NCB
University Press, Vol. 9 No. 5, October 2001.

12. RICHARDS, J. C. and Rodgers, T. S. Approaches and methods in Language Teaching. NY, USA: CAMBRIDGE, 2001.

13. ALMEIDA Filho, J. C. P. Dimensões Comunicativas no Ensino de Línguas. Campinas, Ed. Pontes, 1993.

14. KRASHEN, S. D. Principle and Practice in Second Language Acquisition. Oxford: Pergamon Press, 1982. 